\title{
Evangelismo carcelario en Chile: Análisis socioantropológico de comunidades religiosas en contextos de encierro
}

\author{
Nelson Marín Alarcón \\ Universidad Alberto Hurtado, Santiago, Chile. \\ Email: nmarinalarcon@gmail.com
}

\begin{abstract}
Resumen: ${ }^{1}$ El presente artículo se propone realizar un análisis sobre la formación y expansión de las comunidades religiosas evangélicas dentro las prisiones chilenas. Por medio de un estudio de caso realizado en el CDP Santiago Sur durante el año 2013, se muestra cómo la existencia de estos grupos se asocia a las particularidades del penal y la relación que establecen con otros agentes dentro de prisión. Finalmente, se analiza su crecimiento y legitimidad a partir de los planteamientos teóricos de mayor reconocimiento en la temática.
\end{abstract}

Palabras clave: estudio de caso, pentecostalismo, evangélicos, prisión.

\section{Prision evangelism in Chile: socio-anthropological analysis of religious communities in confinement context}

Abstract: This article proposes an analysis of the formation and expansion of evangelical religious communities in Chilean prisons. Through a case study in the Santiago Sur CDP in 2013, it is shown how the existence of these groups is associated with the peculiarities of prison and the relationship they establish with other actors within the enclosure. Finally, its growth and legitimacy is analyzed from the theoretical approaches of greater recognition in this field.

Key words: case study, Pentecostalism, evangelicals, prison.

\section{Evangelismo carcerário no Chile: análise sócio antropológico de comunidades religiosas em contexto de confinamento}

Resumo: Este artigo propõe uma análise sobre a formação e expansão das comunidades religiosas evangélicas nas prisões chilenas. Através de um estudo de casorealizadono CDP Santiago Surdurante 2013, mostra-se como a existência destes grupos está associada com as peculiaridades da cárcere e a relação estabelecida com outros agentes da prisão. Finalmente, analisa-se seu crescimento e legitimidade a partir das abordagens teóricas de maior reconhecimento nesta temática.

Palavras-chave: estudo de caso, pentecostalismo, evangélicos, prisão. 


\section{Introducción}

Carlo Ginzburg, en la ahora clásica obra llamada "El Queso y los Gusanos" (1999), nos interpela agudamente respecto del valor de aquellos grupos, personas y acontecimientos pequeños que durante siglos han sido considerados como anécdotas en la construcción del discurso historiográfico. ¿Qué puede decirnos un molinero friuliano llamado Menocchio, muerto en la hoguera por orden del Santo Oficio tras una vida transcurrida en el más profundo anonimato, sobre la constitución de lo que podría llamarse la cultura de las clases subalternas o populares del siglo XVI? En estricto rigor, Menocchio no resultaba ni por cerca una persona representativa de su tiempo, sabía leer -habilidad escaza por aquel entonces- y era conocido en su pueblo por las ideas extravagantes que poseía respecto de la constitución del cosmos. De su vida quedan dos procesos en su contra llevados a cabo por la Inquisición y algunos documentos fragmentarios que hablan de detalles de sus negocios y relaciones familiares. Muchas de aquellas fuentes no fueron acuñadas por su puño, sino por el contrario, el de quienes tomaron por labor el desacreditarlo y condenarlo. La pequeña historia de Menocchio se teje a retazos dispares y sobre la base de un detalle que parece intrascendente a la luz de los grandes relatos fundados en el actuar de los hombres de renombre y los acontecimientos históricos de relevancia social.

Pretender generar un análisis valido respecto de la naturaleza religiosa en nuestros días a partir de una comunidad evangélica puntual en un contexto tan particular como la privación de libertad en una cárcel chilena, parece igual de inapropiado que comprender la cultura popular a partir del juicio al molinero Menocchio. Los anhelos de representatividad estadística y la sobreestimación de la variable política sobre el transcurso de la vida de los individuos, ha llevado a desechar dichos puntos de vista hasta épocas recientes donde lo particular parece cobrar nuevos bríos. Los llamados estudios de caso o las metodologías biográficas han logrado generar avances importantes en materia de investigación histórica y social, revalorando la opinión y vivencias de los individuos más allá de su potencial como datos posibles de agregar numéricamente o el valor en sí que poseen por su contenido patrimonial. Como mencionan Santamaría y Marina (1993), este recambio metodológico ha permitido dar nuevo aire a la variedad de sentidos atribuidos por los propios sujetos a los acontecimientos que han vivido, en un contexto social, muchas veces diverso y contradictorio. En este sentido, y siguiendo los planteamientos de Joan Pujadas (2000), este rescate de lo particular y lo testimonial no implica solamente el uso de nuevos tipos de fuentes -en su caso, las fuentes orales-, sino que aporta también nuevos objetos de estudio que implican necesariamente nuevas perspectivas epistemológicas a las ya conocidas en las ciencias sociales y humanas. Ciertamente Ginzburg no pudo interrogar a Menocchio ni sus detractores sino a través de una serie de migajas documentales que dejaron tras su paso por la tierra. En nuestro caso, las facilidades de contacto con aquellos sujetos dentro del penal Santiago Sur son infinitamente superiores. No obstante, el acceso mediante documentación propia de sus custodios - 
Gendarmería de Chile-, la imposibilidad de compartir su vida cotidiana, en una especie de etnografía incompleta y limitada, y el acomodo a las reglas que dominan el régimen interno a la cárcel, imprimen en alguna medida esa sensación de estar reconstruyendo una situación a partir de evidencias diversas y parciales. Las herramientas para generar datos existen pero la imposibilidad de aplicarlas por limitantes estratégicas no deja de producir cierta frustración en quien se acerca a esta realidad tan apasionante como desconocida.

En Chile los estudios religiosos sobre el mundo evangélico aún son escasos y dispersos, siendo la problemática del evangelismo carcelario de gran importancia e impacto público pero de casi nulo interés de parte de historiadores y cientistas sociales ${ }^{2}$. Por su parte, Gendarmería de Chile posee deficiencias administrativas y económicas que han imposibilitado un levantamiento y conservación de información factible de ser analizada con las herramientas metodológicas existentes. La administración carcelaria, tanto chilena como latinoamericana, representa dentro del sector público el último escalón: poco profesional, mala formación, pocos elementos, estructura institucional débil y poco legitima, mostrando dificultades importantes a la hora de contrarrestar la estructura social paralela montada por el mundo delictual en prisión (Carrión, 2007). En dicho escenario, la necesidad de innovar metodológicamente con el fin de realizar un trabajo lo más válido en términos científicos se vuelve un reto permanente.

El presente trabajo, con las limitaciones que la brevedad de su formato impone, representa un intento por analizar la conformación, el funcionamiento y la expansión de las comunidades evangélicas carcelarias en Santiago de Chile. A través de un estudio de caso realizado en el CDP Santiago Sur (Ex-Penitenciaria de Santiago), se busca reflexionar sobre las condiciones existente en el penal y el sistema penitenciario que permiten a ciertas agrupaciones vivir bajo preceptos religiosos con amplia autonomía. La adjudicación y transformación de espacios dentro de los recintos carcelarios, así como la relativa libertad que poseen para generar sus propios mecanismos de administración y disciplinamiento interno, nos llevan a indagar sobre las estrategias de poder que se despliegan entre culturas dominantes y subculturas. De esta manera, la observancia cotidiana de los tipos de interacciones que generan los distintos actores dentro de prisión y la manera en que construyen su testimonio resulta fundamental en la comprensión general del fenómeno.

\section{Metodología}

La presente investigación posee un enfoque cualitativo según el cual, siguiendo a Taylor y Bogdan (1987), podremos generar datos descriptivos sobre el fenómeno estudiado a partir de las palabras de los individuos y su conducta observable. De esta forma, nos focalizaremos en el rescate de la dimensión subjetiva del hablar y la significancia social que otorgan a sus experiencias dentro de la prisión y las dependencias evangélicas (Canales, 2006). 
En términos metodológicos se realizó un acercamiento etnográfico que nos permita describir, analizar ideas, creencias y significados, conocimientos, prácticas de grupos, culturas y comunidades (Gutiérrez y Delgado, 1999). Para ello utilizamos la observación participante dentro de los límites que el régimen interno permite. Ello conlleva visitas y encuentros en las dependencias habitadas por los evangélicos, así como la participación en actividades y rutinas del penal en las que se encuentren involucrados. En este proceso ha resultado fundamental el apoyo de la Oficina de Clasificación de Gendarmería de Chile que ha facilitado sus recursos humanos y materiales para el desarrollo de esta investigación. Sin estas comodidades hubiera sido imposible acceder con libertad y seguridad a las formas de vivir y pensar de los individuos que experimentan el rigor del presidio y la religión.

De igual forma, consideramos pertinente la utilización de una metodología biográfica que permita analizar las trayectorias personales de los sujetos que experimentan la conversión espiritual y habitan en las dependencias controladas por evangélicos. Siguiendo el planteamiento de Joan Pujadas (2000), esta modalidad metodológica tiene una particular afinidad con la etnografía en tanto permite complementar la información obtenida desde las observaciones en el campo con la interpretación que los propios sujetos hacen de sus vivencias. En este proceso la utilización de la técnica de entrevista en profundidad resulta de gran relevancia debido a la flexibilidad que posee en la elección de los tópicos desde los cuales el entrevistador extrae la información contenida en la biografía del entrevistado (Alonso, 1999).

Finalmente, la muestra utilizada es de carácter teórica y noprobabilística pues responde a los criterios de importancia que se detectaron durante el desarrollo del curso investigativo. Las formas de organización interna de las comunidades, los principales liderazgos al interior de la prisión, el personal de Gendarmería directamente relacionado con el habitar de los evangélicos, entre otros, fueron aspectos que se tomaron en cuanta al momento de seleccionar los individuos para ser entrevistados. Cabe destacar que durante este proceso, y debido al perfil de los entrevistados (individuos que cumplen condena por delitos de diversa índole), se utilizaron consentimientos informados en los cuales se explicaba las características del estudio en desarrollo y la confidencialidad de las identidades aludidas. Para ello se otorgó la posibilidad que los entrevistados eligieran el nombre real o ficticio con el que deseaban ser referenciados, así como la facultad de omitir o modificar los datos personales a exponer.

\section{Reflexiones desde un estudio de caso: Sobre lo general y lo particular de las comunidades evangélicas carcelarias chilenas}

Tal como afirma Robert Yin, “el estudio de caso permite a los investigadores retener de forma holística las características significativas de la vida real, acontecimientos tales como los ciclos de vida individuales, los 
procesos organizativos y de gestión, cambios en los vecindarios, las relaciones internas, y la maduración de las industrias” (Yin, 2003: 2). Todo esto permite poner el énfasis en mirar desde lo interno la interacción entre numerosos factores y variables, impactados por cambios altamente dinámicos, en un gran nivel de especificidad (Reyes y Hernández, 2008). De ahí que esta clase de metodología permita ahondar de manera especial preguntas del tipo "por qué" o "cómo" sobre situaciones contemporáneas de las cuales no tenemos control. Esta capacidad explicativa de fenómenos complejos, y las posibilidades de generar teorizaciones sobre procesos sociales a partir de casos únicos o múltiples, convierte al estudio de caso en una herramienta de gran valor (Yacuzzi, 2005). No obstante, se ha criticado a este tipo de estudios los problemas que presenta su capacidad de generalización al no poder reproducir los niveles de confiabilidad y validez propio de una investigación cuantitativa, aun cuando existen parámetros para establecer la utilidad, el valor y el beneficio que conlleva utilizarlo (Martínez, 2006). A pesar de ello, consideramos este tipo de estudio valido para nuestro trabajo puesto que no está en nuestro interés pretender que la comunidad evangélica de la Ex?Penitenciaria sea representativa de todas las comunidades religiosas que se dan en prisión. Somos conscientes de la particularidad que posee este recinto, el más antiguo del sistema público, que lo diferencia considerablemente de las nuevas cárceles concesionadas o los centros de educación y trabajo.

La primera particularidad que nos enfrenta nuestra investigación es la naturaleza del contexto donde se genera. No es misterio alguno que los problemas que poseen en general las cárceles chilenas son similares a los que se reproducen en buena parte de América Latina. Uno de los principales inconvenientes lo constituye el hacinamiento y todas las consecuencia que eso conlleva -riñas de pandillas por disputas territoriales, deterioramiento de servicios higiénicos, insalubridad, etc.-. En el caso del CDP Santiago Sur, si bien la capacidad del recinto rinde por diseño las 3170 personas, hacia el año 2010 alcanzaba cerca de 7200, cifra que ha disminuido considerablemente a niveles de 5500 a mediados del año 2012 debido a las políticas de racionalización y redistribución de población penal. Esta sobrepoblación cercana al 74\% se traduce en que algunas celdas de calles, diseñadas para 5 personas, o en celdas de galería diseñadas para 3 personas, actualmente pueden vivir 15 o más sujetos. En este contexto la tensión por la ocupación de los espacios personales y colectivos se vuelve creciente. El robo doméstico (domestiqueo dentro de la jerga delictual) se establece como una práctica común que induce al enfrentamiento entre individuos y pandillas. Por otra parte, en condiciones de sobrepoblación tales el control del personal de Gendarmería de Chile se vuelve mucho más parcial, dejando la resolución de conflicto internos en manos de sus propios protagonistas.

Por estas condiciones el CDP Santiago Sur es conocido tanto al interior como el exterior de la población penal como una de las cárceles más violentas del país. Recurrentes son las riñas que se suceden en su interior, las cuales han sufrido transformaciones y adaptaciones de acuerdo a los 
cambios acaecidos dentro de la cultura delictual carcelaria ${ }^{3}$. Sin embargo, dicho ambiente de violencia no se agota en los enfrentamientos entre pandillas dentro del sector "óvalo". Es posible afirmar la existencia de condiciones ambientales que facilitan la conflictividad las cuales serían extensivas a buena parte del sistema penitenciario chileno. No obstante, en el caso de la Ex Penitenciaria tenderían a acentuarse según reconocen sus propios habitantes. El testimonio del hermano Cristian podría ser ejemplificador:

"Por eso cuando se habla de rehabilitación yo digo que sólo Dios puede hacer eso, más en una penitenciaria como esta donde se ven tantas cosas. Es difícil poder vivir y uno lo que más le pide a Dios es poder salir vivo algún día de aquí” ${ }^{4}$

Junto con su mala fama por violencia y condiciones infrahumanas de habitabilidad, la Ex Penitenciaria es diferenciable de otras prisiones del país por lo clásico de su diseño arquitectónico. La construcción del recinto en 1843 estuvo fuertemente influenciada por los planteamientos del filósofo y jurista Jeremy Bentham que gozaba de gran aceptación dentro de las elites liberales de la época (Neira, 2004; Saldivia-Maldonado y Caro-Pozo, 2010). Su idea más difundida tenía relación con un dispositivo institucional de control social represivo conocido como el "panóptico" (pan= todo; óptico = ver), el cual, en tanto lugar físico, organizaba arquitectónicamente un encierro en forma circular con una torre de vigilancia central desde la cual era posible observar a los internos separados en sus celdas. Dicha influencia del aspecto vigilante tuvo gran impacto en la disposición octogonal, con radios que nacen de un área de inspección central, del cual surgen pasillos con celdas que albergarían a los internos, que posee actualmente el CDP Santiago Sur.

Tal como afirma Cisternas (1997), la ocupación originaria del recinto se realizó por etapas -al momento de la inauguración únicamente había capacidad de contener a 160 individuos- y sólo en 1856 se finaliza la construcción definitiva del plan original con 520 celdas individuales. Actualmente, y considerando las variaciones en infraestructura y el régimen de gobierno interno, el CDP Santiago Sur posee una capacidad de diseño que alcanza las 3170 personas en dependencias denominadas como calles, galerías y módulos. Tanto las calles como las galerías se encuentran conectadas con el patio central llamado "sector óvalo", debido a la forma que posee, el cual funciona como punto de encuentro entre internos ubicados en distintas dependencias. De igual manera, existe un gimnasio techado que funciona para la recreación de los internos, así como también, para alojar a las visitas semanales de los mismos. El CDP Santiago Sur cuenta además con infraestructura indispensable como el Hospital Interno, enfermerías, edificios de cocinería (edificio del rancho), oficinas y dormitorios para el personal de Gendarmería, oficinas para el área técnica (psicólogos y asistentes sociales), Oficina de Clasificación, sector de guardia interna, casino de oficiales $\mathrm{y}$ funcionarios, etc.

Dicho clima de convivencia, marcado por las deficiencias de infraestructura y administración, sumadas a las disposiciones arquitectónicas del 
recinto, han condicionado en gran medida como se estructuran los pueblos evangélicos al interior de la prisión. Los “pueblos de hermanos”-nombre que otorgan ellos mismos a cualquier tipo de comunidad religiosa evangélica que decide gobernar su vida diaria comunitariamente- se disgregan entre módulos, calles y galerías de manera espontánea. Sin embargo, de acuerdo con la política de clasificación y segmentación de Gendarmería, la composición humana de cada dependencia puede resultar sumamente diferente. Así como hay módulos para internos condenados por delitos específicos que necesitan ser aislados del resto de la población penal (delitos económicos, sexuales, ex uniformados, etc.), también los hay para quienes resultan primerizos en temas criminales. Si tomamos como variable la experticia y trayectoria delictual (en jerga delictual se le denomina Ficha), encontramos que además existen dependencias que concentran a los internos más peligrosos, estas son por lo general las calles y, en especial, las galerías. El preso de calle o galería es astuto, maneja el lenguaje delictual y las estrategias necesarias para poder desenvolverse en ese ambiente. De acuerdo al prestigio de su Ficha logra instalarse en una posición más o menos favorable dentro de la estructuración social propia del mundo carcelario.

Dicha heterogeneidad del mundo delictual difícilmente es posible de caracterizar si no se realiza un seguimiento permanente a los movimientos de internos dentro de la propia prisión. En el caso de nuestra investigación, la posición de observación estuvo dada por el apoyo ofrecido desde la Oficina de Clasificación del recinto que se encarga de rotular al interno, tanto cuando viene recién ingresando, como aquel que lleva tiempo recluido, y colocarlo en la dependencia más adecuada según el régimen interno. A partir de la observancia del acto de clasificar, realizado mediante una entrevista obligatoria por el equipo de Gendarmería, logramos percibir la existencia de distintos perfiles de internos evangélicos según el tipo de dependencia de la que provenían. Así como habían presos de pequeños “pueblos de hermanos” en formación, en los cuales la cantidad de hermano no superaba un par de decenas por dependencia y sólo compartían unos pocos dormitorios que regían bajo su estilo de vida, había otros internos provenientes de dependencias controladas completamente por hermanos y donde el disciplinamiento del régimen establecido por los lideres evangélicos era mucho duro. La obligación de convivir con "gentiles” (no evangélicos) en inferioridad numérica, el tipo de internos que componen la dependencia, el nivel de empoderamiento de los líderes religiosos, el nivel de respaldo que poseen de la autoridad penitenciaria, entre otros, generan perfiles de internos y pueblos profundamente disímiles, con niveles de disciplinamiento conductual y corporal diferenciado, y con posibilidades de movilización de recursos dispares.

Sin embargo, el análisis de casos permite no solo ver la heterogeneidad existente a nivel de pueblos dispersos en la extensión de las dependencias del penal, sino también, la estructuración existente al interior de las propias comunidades. Los pueblos evangélicos de la Ex Penitenciaria poseen una matriz profundamente pentecostal ${ }^{5}$ que se ve manifiesta en alguna 
forma de organización interna y en los principios que sustentan su cosmogonía. No obstante, en ambos casos se logran percibir particularidades que son necesarias de considerar al momento de hacer una justa caracterización y análisis. En el caso de las estructuras organizativas, los pueblos demuestran una matriz común que varía según la extensión misma de la comunidad en cuestión. Así como en una iglesia evangélica pentecostal tradicional del medio libre existe un líder carismático llamado "Pastor”, en las comunidades internas hay alguien en posición homologable llamado "encargado del pueblo". Este último posee cualidades distintivas respecto de la manera de legitimar su liderazgo y ejercer su labor según las condiciones internas. La movilidad de internos es mucho más alta que la movilidad existente entre hermanos de una iglesia en contexto de libertad, más aún en el caso de sus líderes y responsables. La posibilidad de ser trasladado de dependencia y tener que reubicarse en un pueblo de hermanos distinto, de obtener un beneficio carcelario (salida dominical, trabajo, etc.) o de cumplir la condena, promueven mecanismos de reemplazo altamente eficientes que garanticen la supervivencia del grupo. En general lo que opera es la designación de hombres de confianza en orden de jerarquía ("segundo al mando", "tercer al mando", etc.), estos se ocupan de asistir en consejo y acción a los "encargados del pueblo" según las necesidades específicas de la comunidad. De igual manera existe un grupo de hermanos "disciplina” que operan como vigilantes y correctores de las actitudes de los hermanos del pueblo. La promoción de un ideal evangélico y el resguardo de las normas instauradas son su principal preocupación. A pesar de ello, es posible afirmar que el pueblo en su conjunto opera como un organismo vigilante que lleva el ideal del panóptico a la misma intimidad del dormitorio, designando incluso "encargados de dormitorio" que manejan las actitudes y necesidades más cotidianas.

Toda esta complejidad estructural, tanto a nivel de prisión como interno a los propios pueblos, permite vislumbrar ciertas condiciones propias al sistema penitenciario donde se desarrolla la vida comunitaria. Evangélicos en prisión existen en muchos lugares del continente, sin embargo, la especificidad de cada contexto genera la promoción de representaciones, estrategias e ideales diferentes en cada caso. De ahí que al presentarse tal especificidad nazcan de inmediato ciertas tensiones con algunas teorías dominantes al momento de explicar el porqué de la existencia y difusión del evangelismo carcelario en nuestro país.

\section{Expansión evangélica en contextos de encierro: Problemas y debates}

Una de las particularidades que más ha llamado la atención de especialistas, políticos, religiosos y uniformados, ha sido el poder de movilización de recursos autónomos y la capacidad de contención de la violencia que poseen los grupos evangélicos dentro de prisión. Una vez que un “pueblo de hermanos” comienza un proceso de expansión dentro de un 
sector de la prisión, comienza un ciclo de transformaciones del ambiente donde se desenvuelven, en específico nos referimos a la remodelación de la infraestructura. Las paredes deterioradas, baños rotos, suelos destruidos, falta de iluminaria e instalaciones eléctricas, se abordan mediante la gestión de recursos propios - pequeñas donaciones, rifas, venta de comida, diezmo, etc.- que acaban por embellecer el lugar a un nivel que contrasta con el resto de la prisión. Los hermanos solucionan de manera espontánea y sin solicitar recursos a la autoridad competente las deficiencias más evidentes que aquejan al sistema penitenciario. En la medida que la cantidad de internos que se suma a las comunidades va creciendo, ya sea por conveniencia material o conversión espiritual, el pueblo va capturando más espacios al punto que puede tomar toda una dependencia. Una vez que el pueblo se ha expandido lo suficiente, universaliza su régimen de vida e intensifica la vigilancia en el cumplimiento de los ideales de hermanos que se promueven. Dentro de un pueblo todos viven según la rutina religiosa instaurada, con horarios rígidos y roles estructurados. Se busca neutralizar todos los marcadores culturales propios del mundo delictual mediante un disciplinamiento del cuerpo y el espíritu. Los hermanos visten de traje y corbata todo el tiempo, usan el cabello en extremo corto y andan afeitados. Se vigila no solo su apariencia por medio de inspecciones constantes, sino también, se observa su comportamiento con atención, deben modificar su lenguaje (no utilizar la jerga delictual llamada “coa”), no fumar, drogarse ni mantener conflictos con el resto de la población penal. Este último aspecto, el que llevan a cabo mediante la aplicación de una red de contención que busca canalizar los conflictos y evitar los enfrentamientos de sangre, es lo que más interesa a Gendarmería según las necesidades propias del régimen interno de la prisión. El interno que ingresa a un pueblo de hermanos y decide "convertirse" a la religión evangélica, se abstrae de la conflictividad y relaciones de fuerza que priman dentro de la estructuración social propia del mundo delictual.

Explicar la naturaleza de esta expansión de pueblos evangélicos que transforman sectores completos dentro de las prisiones, imponiendo gobiernos internos y actuando dentro de la más profunda autonomía y autarquía, resulta en términos teóricos un gran desafío. Ciertamente cuando se les consulta a ellos mismos sobre el valor y explicación que le otorgan a la expansión evangélica dentro de la cárcel, la interpretación religiosa centrada en el cambio de trayectoria de vida surge de inmediato. El hermano de prisión mira su propia historia desde la dualidad propia del universo pentecostal, en donde el mundo se divide entre Dios y Satanás, el bien y el mal, la gracia y el pecado. En dicho contexto, la criminalidad se explica desde la falta de Dios y sólo la salida a su encuentro puede generar cambios significativos a la hora de un potencial desistimiento delictual. Esta conversión espiritual conllevaría la interiorización de parámetros normativos que normalizarían las conductas dentro de un camino socialmente aceptado. El converso es un hombre nuevo que valora el rol del trabajo honesto, la familia, la pureza del cuerpo y la vida religiosa, todas aquellas conductas afines al desistimiento criminal. 
Esta interpretación, ciertamente la más difundida entre quienes avalan y se sorprenden con los frutos inmediatos que genera la acción evangélica en contextos de encierro -hay quienes hablan incluso de impacto en indicadores de reinserción social, aunque para esto último no hay cifras ni estudios concretos-, nos direcciona de inmediato hacia los postulados más clásicos de la sociología de la religión. Probablemente uno de los planteamientos relativos a la religión más reconocidos de Max Weber (1994) ha sido su intento de vincular ética religiosa y comportamiento económico. Por medio del estudio de las “sectas protestantes” norteamericanas, Weber logra identificar actitudes y valores que promoverían un estilo de vida proclive al éxito económico dentro de un sistema capitalista. Para el autor, los bautistas norteamericanos -cuyas características extrapola al resto del mundo protestante- poseen un comportamiento sectario que favorecería la promoción de un estilo de vida austero y acumulativo. Las sectas -para Weber- tendrían como principal característica la oposición al carisma hierocrático de la iglesia, la cual, en su calidad de dispensadora democrática de bienes de salvación, tiende a integrar bajo su alero a justos y pecadores (Weber, 1999). Por el contrario, la secta protestante tiende a demandar un alto nivel de cualificación desde el punto de vista religioso, exigiendo conductas y dotes valorados por la comunidad, hecho que propiciaría la formación de alguna clase de acuerdo libre entre sus miembros. El protestante es probado permanentemente por sus pares y por sí mismo, valora el esfuerzo personal y rechaza lo suntuoso aun cuando en la acumulación económica encuentre signos de realización espiritual. En la práctica poseen más propiedad y se muestran más proactivos en la adquisición de altos cargos en comparación con lo católicos. Tienen mejor formación académica y ante la exclusión de puestos de poder tradicionales tienden a volcarse a la industria, lugar desde donde pueden desarrollar más su creatividad y emprendimiento (burguesía industrial). En este contexto, el "espíritu del capitalismo" que se desprende de la racionalización de la producción y la ganancia, encuentra un correlato en la "ética protestante” que favorece un comportamiento ascético, extramundano y que mira el éxito como símbolo de justicia y rectitud espiritual. Tal como afirma el propio Weber, "han sido siempre los protestantes (singularmente en alguna de sus confesiones que trataremos más adelante) los que, como oprimidos u opresores, como mayoría o como minoría, han mostrado singular tendencia hacia el racionalismo económico, tendencia que ni se daba ni se da entre los católicos, en cualquier situación en que se encuentren. La razón de tan distinta conducta deben buscarse, pues, en una determinada característica personal permanente y no solo en una cierta situación histórico-política de cada confesión” (Weber, 1994: 32-33).

Esta vinculación entre ética religiosa y comportamiento económico parece ser muy apropiada al momento de explicar las condiciones distintivas que posee el mundo evangélico carcelario respecto del mundo gentil. Sin embargo, el estudio de caso y ciertas consideraciones evidentes generan reparos que es necesario enunciar con el objetivo de no sobredimensionar los alcances de la teoría. Por una parte, los planteamientos de Weber surgen en un contexto sumamente diferente al que nos en- 
contramos abordando. Bastante poco tienen en común las sectas protestantes norteamericanas de principios de siglo XX en comparación de los grupos evangélicos y pentecostales latinoamericanos. Estos últimos surgen específicamente al alero de una modernización contradictoria que intensificó la marginalidad urbana dentro de un proceso constante de migración campo-ciudad. Si bien el pentecostalismo no apunta a trabajar sobre un sector socioeconómico específico, históricamente ha tenido mayor aceptación en los segmentos bajos de la sociedad, al punto que Christian Lalive lo denominó como un "refugio de masas” para quienes sufrían el desarraigo y la miseria propias de un proceso de migración desde el campo a la ciudad durante el proceso modernización de mediados de siglo XX chileno (Lalive, 2009). Esta vinculación con los sectores más desfavorables todavía permanece aun cuando las condiciones sociales, económicas y políticas actuales sean radicalmente diferentes a las analizadas por Lalive en los años 60. Para Miguel Ángel Mansilla, esta relación con la pobreza ha llevado con el tiempo a construir un estereotipo despreciable del pentecostal que él denomina con el apelativo de canutofobia. En sus palabras afirma que "En Chile la mitificación asociada de evangélicos y pobreza, es decir la afirmación que los evangélicos son pobre, por lo tanto rechazables, esto tiene una connotación clasista y racista, ya que este rechazo se hace a los pentecostales, y no a los protestantes misioneros o históricos” (Mansilla, 2007b: 58). A lo anterior habría que agregar las impugnaciones de machistas y fanáticos por su moralismo rígido y la fuerte inclinación a la predicación- que configurarían un imaginario negativo sobre lo que es ser pentecostal. Sin embargo, si bien es posible establecer que el pentecostalismo se expande no solo en contextos de pobreza, el propio Mansilla reconoce que a lo largo de la historia ha tenido un gran arraigo en los sectores populares de la sociedad. Desde sus inicios "los pentecostales eran los pobres despreciables, aquellos relacionados con los "huachos", las “chinas” y los "rotos”. Estos eran los pauperizados; categorizados, no sólo por la situación económica que se vivía en aquel entonces, es la asociación negativa entre trabajador y pobreza, representan el segmento inmovilizado de la sociedad chilena, son un grupo peligroso, que viven en regiones de escuálidos deseos y malvada miseria” (Mansilla, 2007a: 11). Hoy su dominio en la estructura social se ha diversificado conforme se han expandido los grupos medios de la sociedad, lo que no quiere decir que hayan perdido el lugar privilegiado que poseen en los barrios populares de las comunas más desfavorecidas socioeconómicamente. Para el pentecostal de estos sectores, “en el hacinamiento y la pobreza en que viven “comenzar a caminar en el Evangelio” es parte de su lucha diaria contra el maltrato, el desempleo y el subempleo, la violencia familiar, el alcoholismo, la droga, la prostitución y la delincuencia” (Mansilla, 2007b: 59)

Por otra parte, al analizar la propia realidad de las comunidades evangélicas del CDP Santiago Sur, nos damos cuenta que el éxito y permanencia dentro de las mismas depende de múltiples factores que no necesariamente pasan por una interiorización espiritual específica. Por una parte, al ser la movilidad dentro del penal muy elevada, la posibilidad de permanecer de forma constante dentro de un pueblo de hermanos es relativamente baja. 
Los pueblos son autónomos unos respectos de otros, por lo que el acceso a redes de distribución de recursos laborales y materiales puede variar de caso en caso. No obstante, es posible que un hermano con suficiente capital social dentro del mundo evangélico de la prisión logre instalarse de mejor manera que otro que recién se está internando en dichas redes. En dependencias donde viven 400 hermanos no todos pueden ocupar cargos de prestigio y entablar relaciones duraderas con las iglesias externas -que por lo general ingresan otorgando alguna clase de apoyo material y/o espiritual- que permitan reproducir la dinámica de comunidad religiosa en el medio libre. La mayor parte de los hermanos que salen a la libertad siguen practicando la fe en términos variables según han logrado instalarse en el mercado del trabajo formal y se han distanciado de sus vínculos delictuales de origen. Ciertamente el llevar un "buen testimonio", vale decir, el haber demostrado con hechos visibles que la conversión religiosa es profunda y legitima en la propia vida, contribuye de manera decisiva a la integración de los hermanos dentro de las redes solidarias existentes y que podrían tener un efecto positivo en la recomposición de los vínculos familiares y laborales necesarios a la hora del desistimiento delictual. No obstante, las posibilidades de realizar dicho proceso de manera masiva son aún reducidas y condicionadas al tipo de relación personal que pueda tener el individuo con los líderes religiosos.

Por otra parte, un elemento importante que no es habitualmente considerado es el valor que tiene en esta preservación y expansión evangélica el disciplinamiento. Como ya hemos mencionado, el pueblo evangélico lleva el ideal del panóptico a la intimidad más inmediata, regula los comportamientos cotidianos hasta su más mínima expresión y despliega un aparataje correctivo de precisión única. De ahí que sea importante considerar los estudios de Michel Foucault (2005) cuyo foco central en su planteamiento se haya en la configuración de las estrategias de poder sobre el cuerpo y en la racionalización de las instituciones que aplican el castigo. En este sentido, el planteamiento de Foucault nos resulta doblemente interesante en tanto nos permite analizar al castigo desde una mirada diferente a la de Durkheim -para Foucault el castigo es impuesto a la población y no algo que se haya inserto en los sentimientos colectivos y que canaliza la energía moral-, así como también, indagar en la naturaleza de la prisión moderna tanto histórica como socialmente.

Por medio de un estudio minucioso y ampliamente documentado, Foucault concentra su atención en las relaciones de poder que se dan de manera interna dentro del proceso penal, evitando afirmaciones totalizante y estructurales. De esta forma, y siguiendo la línea de Garland (1999), podemos decir que realiza un "fenomenología del control penal" por medio de una acuciosa reconstrucción de los cambios en el sistema penal europeo entre el siglo XVII al XIX- desde el análisis del complejo entramado de relaciones sociales y discursos propios de los fenómenos. En su obra más conocida sobre la materia (Vigilar y Castigar), Foucault busca desde un primer capítulo establecer una diferenciación mediante el análisis de dos documentos que describen dos situaciones: en primer lugar, el suplicio de 
Damiens, hombre torturado hasta la muerte públicamente por una acusación de regicidio en Francia; y en segundo lugar, un reglamento de horarios de una prisión parisense en que se detallan las labores de los internos durante el día. Ambos documentos son del siglo XVIII y separados por solo por un lapso de 80 años y le ayudan a Foucault a establecer la pregunta que pretende resolver a lo largo de su estudio: cómo es posible que formas de castigo tan disimiles puedan haberse sucedido en tan poco tiempo, o en términos más específicos, cómo es que se pasa desde el castigo aplicado al cuerpo, con un fuerte sentido de venganza y moralización publica, al encierro y el aislamiento controlado por una institución racionalizada como la prisión. Ciertamente ambas son formas de castigo, pero hay una evolución importante tanto en la forma como el contenido, elementos que Foucault logra identificar e insertar en su teoría sobre el poder que actúa sobre el cuerpo (microfísica) y el valor del conocimiento (especialistas médicos y sociales, en especial, en el surgimiento de una nueva ciencia llamada criminología). El paso del patíbulo a la penitenciaria significa para Foucault un cambio en la forma en que opera el poder en la sociedad moderna. Del ensañamiento sobre la carne se pasa a la disciplina mediante el control permanente al interior de la prisión. Esta nueva tecnología de poder implica la necesidad de conocer al criminal, comprender los motivos que explican su actuar e intervenir para corregirlo, de ahí que los norteamericanos llamaran tan certeramente a este tipo de establecimiento como "correccionales". El objetivo es ahora el "alma” del individuo, la fuerza física es reemplazada por el control rutinario, el examen permanente de especialistas -la ciencia y el conocimiento como aliados en la ejecución del mecanismo de poder- y la disciplina permanente. Tal como afirma el propio Foucault, "La prisión debe ser un aparato disciplinario exhaustivo. En varios sentidos: debe ocuparse de todos los aspectos del individuo, de su educación física, de su aptitud para el trabajo, de su conducta cotidiana, de su actitud moral, de sus disposiciones; la prisión, mucho más que la escuela, el taller o el ejército, que implican siempre cierta especialización, es “omnidisciplinaria”. Además la prisión no tiene exterior ni vacío; no se interrumpe, excepto una vez acabada totalmente su tarea; su acción sobre el individuo debe ser ininterrumpida: disciplina incesante. En fin, da un poder casi total sobre los detenidos; tiene sus mecanismos internos de represión y de castigo: disciplina despótica. Tiene que ser la maquinaria más poderosa para imponer una nueva forma al individuos pervertido; su modo de acción es la coacción de una educación total” (Foucault, 2005: 238)

Ciertamente lo más interesante del planteamiento de Foucault es la idea de disciplinamiento y de microfísica del poder. Algo que es posible percibir al interior de las comunidades religiosas evangélicas, y entre estas y el resto del mundo del CDP Santiago Sur, es la existencia de redes de poder que permean a los individuos y se ejecutan a manera de estrategia. En este sentido, y tal como menciona Foucault (1992; 2000), este poder no es posible atribuirlo a una persona o cargos específicos que lo poseen a manera de propiedad y lo ejecutan de manera vertical en forma de represión. Por el contrario, toda la comunidad se hace parte de ese poder, siendo tanto víctima como victimaria aun cuando los beneficios que dicho poder conlle- 
va sean repartidos de formas desiguales. El poder ante todo se ejerce a manera de estrategia diferenciada según la posición dentro de la prisión que se ocupe. Frente a los propios hermanos, el resguardo frente a la conflictividad interna o el acceso a fuentes de recursos materiales y humanos parece sumamente atractiva. Por su parte, para Gendarmería y el resto de las autoridades penales la posibilidad de embellecimiento y control de la violencia intrapenitenciaria resulta de gran interés funcional. Sin embargo, conviene aseverar que tampoco se debe caer en la hiperracionalización de las conductas intrapenitenciarias. Aunque la astucia sea una de las cualidades más valoradas dentro del mundo del mundo delictual, no todo movimiento es factible de ser encasillado dentro de una acción racional calculada para obtener un fin explícito. Ciertamente dentro de la prisión existen normas y valores, que no se corresponderán con la normatividad mayoritaria de la sociedad, pero que son respetados y condicionan el actuar de los individuos. De igual manera, las trayectorias individuales son sumamente importantes a la hora de establecer las motivaciones o circunstancias en las cuales un individuo puntual decide ingresar y someterse a un "pueblo de hermanos”. Así como hay quienes instrumentalizan dichos espacios para escapar de las amenazas de muerte o conflictos que poseen con el resto de la población penal, adhiriendo teatralmente a los postulados y rutinas evangélicas (a estos se les denomina “hermanos encarpados”), hay quienes realmente pueden encontrar redes de apoyo emocional y sentido de pertenencia en dichos lugares. De ahí que sea importante establecer que no solo el disciplinamiento ni la hiperracionalidad pueden explicar de manera satisfactoria el porqué de la expansión de un pueblo evangélico.

De igual manera, la existencia de redes de poderes y luchas de posicionamiento dentro de la prisión, y dentro de los mismos pueblos evangélicos, podría sugerirnos la posibilidad de analizar el fenómeno del evangelismo carcelario en tanto "campo". Con esto nos referimos al valioso aporte realizado por Pierre Bourdieu (1995; 2002) en su intento por explicar el origen y funcionamiento del campo religioso. Para comprender como funciona esta clase de campo es necesario tener en cuenta que es lo que Bourdieu entiende por "campo" dentro de su teoría. Para Bourdieu, un campo puede definirse como "una red o configuración de relaciones objetivas entre posiciones. Estas posiciones se definen objetivamente en su existencia y en las determinaciones que imponen a sus ocupantes, ya sean agentes o instituciones, pos su situación (situs) actual y potencial en la estructura de la distribución de las diferentes especies de poder (o capital) -cuya posesión implica el acceso a las ganancias específicas que están en juego dentro del campo- $y$, de paso, por sus relaciones objetivas con las demás posiciones (dominación subordinación, homología, etc.)”(Bourdieu, 1995: 64). Para el autor, en las sociedades actuales, altamente diferenciadas, el cosmos social está compuesto por una cantidad importante de microcosmos que actúan en relativa independencia del funcionamiento de los demás, y en donde las relaciones objetivas se dan en el marco de lógicas y necesidades específicas. El campo (religioso, económico, académico, político, etc.) es básicamente un lugar de luchas entre fuerzas que buscan conservar o cambiar la configuración de sus posiciones según un principio 
de jerarquización favorable a sus propios productos. En él subyace la posibilidad de que los individuos, actuando solos o colectivamente, puedan ejercer algún tipo de "capital” -habilidad, conocimiento, etc.- que funcione como factor eficiente, como arma o apuesta, que le permita posicionarse de mejor manera en el campo. Como afirma el propio Bourdieu, el capital, "permite a su poseedor ejercer un poder, una influencia, por tanto, existir en un determinado campo, en vez de ser una simple "cantidad deleznable" (Bourdieu, 1995: 65)

El planteamiento de Bourdieu resulta interesante en nuestro caso por la idea de la existencia de luchas de posiciones en donde se pone en juego ciertas formas de capital. Ciertamente los grupos evangélicos manejan recursos y conocimientos -el dominio de la palabra bíblica, por ejemploque les ayudarían a obtener lugares de privilegio en algunas circunstancias. En efecto, esta lógica es más fácilmente perceptible al interior de las mismas comunidades donde el despliegue de ciertos marcadores culturales y conductuales les permiten a los individuos acceder a beneficios que son restringidos para el resto de la comunidad. Como menciona Joaquín Algranti(2011) para el caso de las comunidades evangélicas carcelarias en Buenos Aires, las posiciones que ocupen los hermanos evangélicos dentro de una comunidad específica configuran también un espacio de punto de vista, en donde la manera de pertenecer y relacionarse con el "Evangelio" depende directamente del lugar que se ocupe en él (sub-campo religioso). No obstante, al modo que Pierre Bourdieu lo explica, dentro de la Ex Penitenciaria difícilmente podría hablarse de la existencia de un campo religioso entre denominaciones religiosas. Si bien es posible percibir la presencia y actuar de distintas religiones -existe la Capellanía católica, acciones pastorales, misiones de predicación de denominaciones diferentes, donaciones de iglesias, etc.-, los ámbitos de acción de cada religión no necesariamente entran en una lógica de competencia por medio del despliegue de un capital simbólico vinculado con algún tipo de conocimiento o dogma de salvación. Por el contrario, salvo el mundo evangélico que posee una participación activa en la estructuración social y la segmentación general de la prisión (Gendarmería instrumentaliza sus espacios para anular el actuar de ciertos delincuentes conflictivos), el resto de las religiones opera con bastante armonía y sin mayores pretensiones que mantener los ritos y doctrinas propias de su fe. Efectivamente existen prejuicios entre ellos respecto de la forma que poseen a la hora de abordar la labor evangelizadora, no obstante, en la mayor parte de los casos no buscan desplegar estrategias propiamente religiosas con el fin de contrarrestar o deslegitimar el avance de otra denominación dentro del mismo espacio. Es puntualmente el mundo evangélico por medio de sus estrategias en múltiples niveles (no necesariamente religiosas o simbólicas) el que más se esfuerza por ganar terreno dentro de la prisión, aunque siempre desde una lógica de co-gobierno interno. Esto último es de suma importancia en tanto, si seguimos el planteamiento de Bourdieu (2010), las iglesias en general han cumplido la labor de mantenimiento del orden político mediante el reforzamiento simbólico de las divisiones de este orden. Para el caso de nuestra investigación, si bien es posible encontrar una pretensión de legitimar la posición superior 
del personal de Gendarmería de parte de las comunidades evangélicas, recalcando el respeto por la autoridad uniformada (no antes que la espiritual), lo que en la práctica se da es la búsqueda de una autonomía que logra constituir un poder paralelo al amparo de las limitaciones evidentes que tiene el gobierno del poder político interno al penal.

Finalmente, una interpretación que no considere la variable sociohistórica correrá el riesgo que aislar los casos estudiadosde los procesos estructurales que dan forma a las distintas sociedades en determinadas épocas. En el caso del surgimiento y expansión de las comunidades evangélicas en prisión, los planteamientos más interesantes van en la dirección de vincular dicho fenómeno con la emergencia de una nueva forma penalidad propia de los Estados neoliberales de fines del siglo XX (Daroqui, Bouilly y Motta, 2009). Dicha crítica afirma la existencia de un sistema de penalidad neoliberal marcado por la estigmatización y represión a los pobres, donde el Estado somete a la población penal a condiciones infrahumanas de existencia dentro de las cárceles y minimiza progresivamente la extensión de las políticas orientadas a una reintegración social sana y efectiva (Tijoux, 2011). Tomando como eje la contribución realizada por Loïc Wacquant (2004; 2007), se sostiene que junto a la modernización económica, la restructuración del capitalismo financiero y la expansión de las nuevas tecnologías del conocimiento, se ha producido una "modernización de la miseria” que ha impulsado el ascenso un nuevo régimen de desigualdad y marginalidad urbana. Mientras en antaño la pobreza poseía la particularidad de ser cíclica o residual, geográficamente difusa y concentrada en la clase obrera, hoy parece ser permanente y desconectada de las tendencias macroeconómicas. Sobre esta miseria estructural, concentrada en barrios y poblaciones definidas, se concentra la represión estatal por medio de la criminalización de su condición, potenciando las tasas de encarcelamiento de manera acelerada. Tal como el propio Wacquant afirma, “el nuevo sentido común penal que apunta a criminalizar la miseria -y por esta vía, normalizar el trabajo asalariado precario-, concebido en Estado Unidos, se internacionaliza en formas más o menos modificadas e irreconocibles (a veces incluso por los mismos que las propagan), a semejanza de la ideología económica y social basada en el individualismo y la mercantilización, de la que es, en materia de "justicia”, la traducción y el complemento” (Wacquant, 2004: 23). La difusión de modelos represivos como la Tolerancia Cero o las leyes del Three Strikes son reflejo de esta tendencia.

La estigmatización de la pobreza y la represión policial en barrios marginales, se traduce rápidamente en presión contante y posterior colapso del sistema penitenciario. Como detalla el trabajo de Jorg Stippel (2006), el sistema de cárceles chilenas se caracteriza por ser altamente saturado y segregador. En su mayoría agrupa a jóvenes de poblaciones pobres que cumplen altas condenas por delitos que en su mayoría atentan contra la propiedad privada, convirtiendo a los recintos, siguiendo la línea de Christopher Birkbeck (2009), en “prisiones-almacenes” que custodian delincuentes, reproducen la criminalidad y se desvinculan de todo fin refor- 
mador. En dicho escenario, la emergencia de las comunidades religiosasresponde a la consolidación de un autogobierno evangélico producto de una institucionalidad pública, representada por Gendarmería, que se declara incapaz de solucionar las problemáticas de la población penal. De esta forma, la expansión de los “pueblos de hermanos” se legitima mediante su capacidad de autogestionar mejoras en la deteriorada infraestructura del penal, así como el disciplinamiento microfísico que realizan sobre los internos que habitan sus dependencias.

Si la interpretación weberiana pone el énfasis en el impacto que la interiorización de una ética religiosa genera en un comportamiento práctico proclive al desistimiento delictual, el planteamiento centrado en la terciarizacion del gobierno interno se focaliza en el pragmatismo de la institución carcelaria frente a las necesidades inmediatas que sufre.Se consolida así un funcionalismo que comprende la emergencia de comunidades religiosas como otra vía de disciplinamiento (espiritual-corporal) con beneficios evidentes tanto para la institución como para los internos: los primeros mantienen el gobierno interno a la prisión al menor costo posible, mientras que los segundos lo hacen con el objeto de gozar o perpetuar beneficios que el resto de la población penal no religiosa no posee. Sin embargo, tal como se pudo apreciar durante nuestra estadía en el CDP Santiago Sur, la existencia de este acuerdo tácito entre comunidades religiosas y Gendarmería de Chile que condiciona el movimiento de personas y recursos económicos (permiso para ingreso de materiales de construcción, autorizaciones para generar actividades, facilidades en el régimen de visitas, etc.), no explica por si solo la emergencia y expansión de estas comunidades en las últimas décadas. Ello sería reproducir el discurso de Gendarmería que entiende el actuar evangélico como una teatralidad que deja traslucir una nueva forma de astucia y engaño, ambas calidades valoradas dentro de la subcultura delictual. La figura del "hermanito canalla”, como quien adopta las características del estereotipo evangélico para eludir la conflictividad interna o acceder a beneficios conductuales, se generaliza e instala la sospecha permanente que cuestiona la posibilidad de cambio de vida. No obstante, y siguiendo el planteamiento de Irving Goffman (1970), la generación de representaciones estigmatizada entre internos y custodios que comparten la vida cotidiana es algo recurrente dentro del funcionamiento de las instituciones totalizantes. De ahí que sea necesario complementar dichas percepciones con el análisis de la expresión y sentido del hecho religioso, el cual, como hemos mencionado anteriormente, posee particularidades que lo distinguen de cualquier otro hecho social.

\section{Consideraciones finales}

Como hemos podido apreciar a lo largo de estas breves páginas, un estudio de caso de tipo etnográfico en un contexto tan particular como el nuestro puede ayudarnos a realizar importantes consideraciones teóricas y metodológicas relativas al estudio de la religión en el mundo de hoy. Aunque nuestra intención no ha sido la de generar un modelo explicativo de 
gran alcance, si creemos que las teorías y metodologías, en especial aquellas que se sostienen sobre los hombros de intelectuales consagrados en nuestro campo, deben ser puestas permanentemente en tela de juicio sin temor a relaborarlas o descartarlas. Con este acto critico no creemos bajo ningún aspecto superar los postulados de ninguno de los autores trabajados, sino por el contrario, otorga nueva vigencia en la medida que sus conceptos pueden ser repensados en realidades muy diferentes a las que les dieron origen.

Por medio de este trabajo hemos intentado establecer de manera empírica como el estudio de caso permite construir planteamientos explicativos por medio del análisis de realidades particulares. A través de una mirada aguda en torno a las formas de vida propias de las comunidades evangélicas dentro de un penal en Santiago de Chile, se nos ha hecho visible el hecho de que fenómenos extendidos en variados países y localidades deben ser analizados a la luz de los procesos históricos y las condiciones materiales que le son propias a su espacio. Para el caso del CDP Santiago Sur, tanto las características físicas del espacio (infraestructura), como el perfil de internos que recibe, configuran formas específicas de ser hermano carcelario. Esto se vuelve más evidente al analizar testimonios que vislumbran la construcción de una identidad diferente al evangélico o pentecostal que se desenvuelve en el medio libre. La conversión, los tránsitos, las rutinas religiosas, la forma de subsistir en un escenario hostil, hacen de los pueblos de hermano una realidad heterogénea en su interior.

Sin lugar a dudas, el principal hecho problemático que ha expresado el crecimiento de estos "pueblos de hermanos” en prisión tiene relación con sus causas y legitimidad. Con el objeto de dilucidar estos puntos hemos analizado la problemática a la luz de las principales teorías que abordan los problemas del encierro dentro de nuestras sociedades. Importante es recalcar que la elección de dichas interpretaciones y los posteriores cuestionamientos que se hacen de ellas, se sostienen en las experiencias y discursos que fueron posibles de identificar durante el proceso etnográfico realizado en el CDP Santiago Sur. Tanto el valor de la ética religiosa, los dispositivos de disciplinamiento, la competencia por beneficios y la relevancia del estado actual del sistema penitenciario, nos han llevado a valorar y complementar aquellos aportes que se demuestran aun vigentes.

En una última reflexión cabe mencionar que la investigación en materias religiosas necesariamente se debe poner en sintonía con los planteamientos de múltiples disciplinas que contribuyan a desentrañar la trama tan compleja que teje el fenómeno religioso. Este acto mismo nos permitiría superar las barreras tradicionales que se han acusado a los estudios de caso y de realidades microhistóricas. El particularismo cobra sentido cuando deja de ser sólo anécdota, cuando se pone en dialogo con las estructuras que condicionan el tiempo histórico específico en donde se desenvuelven los fenómenos. En el caso puntual de nuestra investigación, imposible no es mencionar que el problema de la expansión del evangelismo carcelario difícilmente podría ser explicado si no se tomara en cuenta el rol que ha 
asumido en las últimas décadas el Estado chileno respecto del tratamiento de su población carcelaria. En este punto se cruzan la modernización de un sistema penitenciario, cargado de una ideología determinada, con el crecimiento de un evangelismo pentecostal que comienza a permear las instituciones públicas a partir de su derecho a asistir espiritualmente a sus feligreses. La presencia de estas agrupaciones en hospitales, centros de detención, así como en las Fuerzas Armadas y de Orden y Seguridad, abre nuevas posibilidades de estudio y análisis. 
Polis, Revista Latinoamericana, Volumen 15, $N^{\circ}$ 43, 2016

\section{Notas}

${ }^{1}$ Las reflexiones de este artículo se enmarcan en el desarrollo de la investigación Fondecyt $\mathrm{N}^{\circ} 11130281$ titulada: "Religiosidades en la ciudad: nuevos movimientos religiosos y demandas sociales en el Gran Santiago: 1990-2012”.

${ }^{2}$ Dentro de aquellos esfuerzos por analizar dicho fenómeno cabe destacar las empresas establecidas por Concha (2009) y Jiménez (2008).

${ }^{3}$ Durante el año 2012, Patricio Marchant dirigió un informe de práctica profesional que se centró en el análisis de las variaciones en las formas que se establecían las riñas al interior del CDP Santiago Sur. Según los resultados obtenidos, era posible afirmar una especie de transición desde el clásico combate de los "estoques” (especie de esgrima delictual) al "atentado por sorpresa". El informe final lleva por nombre "Riñas en el CDP Santiago Sur: Un muro más en la Peni”, y se encuentra próximo a ser publicado.

${ }^{4}$ Hermano Cristian, 41 años, hermano de la sección de los módulos, condenado a 8 años por robo con intimidación, 14 de diciembre de 2012.

${ }^{5}$ Por pentecostales se entiende a un sistema de creencias, emparentado a la gran familia protestante y derivado del metodismo, que en las últimas décadas se ha constituido como la religión más dinámica y expansiva del mundo. En términos religiosos, se caracteriza por la manifestación de los dones o "carismas” (don de lenguas, profecías, sanaciones, etc.), así como la promoción de un estilo de vida mesurado y ascético, que, afirman, los distancia del resto de las personas. Ello se basa en la diferenciación que realizan entre su propia comunidad, tocada por la gracia Divina, y el resto del "mundo". Todo ello en una visión espiritualizada de la realidad donde se expresan fuerzas espirituales antagónicas (Dios y lo demoniaco) dentro de la cotidianeidad de los individuos (Cantón, 2002; Marín, 2010; Watanabe, 2009; Bahamondes y Marín, 2013). 


\section{Bibliografía}

Alonso, Luis (1999), "Sujeto y discurso: El lugar de la entrevista abierta en las prácticas de la sociología cualitativa”. En: Juan Gutiérrez y Juan Delgado (Eds.,. Métodos y técnicas cualitativas en Ciencias Sociales. Edit. Síntesis Sociológica, Madrid.

Algranti, Joaquín (2011), "Ser e parecer en el mundo carcelario-evangélico: Sobre las condiciones sociales de definición de la realidad”. En: Religião e Sociedade, $\mathrm{N}^{\circ}$ 31(2), Río de Janeiro

Bahamondes, Luis y Marin, Nelson (2013), "Miedos sociales y religión: una reflexión a partir del pentecostalismo urbano chileno". En: Revista Sociológica, año 28, n 78, México.

Birbeck, Christopher (2009), "Prisiones e internados: Una comparación de los establecimientos penales en América del Norte y America Latina”. En: Crimen e inseguridad. Políticas, temas y problemas en las Américas, Lucia Dammert (edit.). Ediciones FLACSO, Santiago de Chile.

Bourdieu, Pierre (2002), Campo de poder, campo intelectual. Editorial Montresor, Buenos Aires.

Ídem (2010), Génesis y estructura del campo religioso. En: La eficacia simbólica. Religión y Política. Editorial Biblos, Buenos Aires.

Ídem (1995), Respuestas por una antropología reflexiva. Grijalbo, México.

Canales, Manuel (2006), “Presentación”, En: Manuel Canales (coor.). Metodologías de investigación social. Introducción a los oficios. LOM Ediciones, Santiago.

Cantón, Manuela (2002), "La construcción social de la sospecha. Minorías religiosas contemporáneas y procesos de exclusión”. En: Estudios sobre Culturas Contemporáneas. Época II, Vol. VIII, N 15 . Centro Universitario de Investigaciones Sociales, Universidad de Colima, Red A. L y C, México.

Carrión, Fernando (2007), Editorial: ¿¿Por qué todos los caminos conducen a la miseria del panóptico? En: Revista Latinoamericana de Seguridad Ciudadana, Mayo, $\mathrm{N}^{\circ}$ 1, FLACSO, Ecuador.

Cisternas, Jaime (1997), Historia de la cárcel penitenciaria de Santiago: 1847 - 1887. Tesis para optar al grado de Licenciado en Historia, Facultad de Historia, Geografía y Ciencias Políticas, Pontificia Universidad Católica de Chile, Santiago.

Concha, Nury (2009), Libertad entre los cautivos: aproximación al proceso de construcción de la identidad carcelaria pentecostal en el Complejo de Cumplimiento Penitenciario en Alto Hospicio. En: Voces del Pentecostalismo 
Latinoamericano IV. Identidad, teología, historia. Relep, Concepción.

Daroqui, Alcira; Maggio, Nicolás; Bouilly, Maria del Rosario; Motta, Hugo. (2009), “'Dios agradece su obediencia': la 'Terciarización’ del gobierno intra muros en la cárcel de Olmos”. En: XXVII Congreso ALAS (Asociación Latinoamericana de Sociología), Buenos Aires.

Foucault, Michel (1992), Microfísica del poder. Ediciones La Piqueta, Madrid.

Ídem (2000), “Poderes y estrategias”. En: Un dialogo sobre el poder y otras conversaciones, Alianza editorial, Madrid.

Ídem (2005), Vigilar y castigar. Nacimiento de la prisión. Siglo XXI, Madrid.

Garland, David (1999), Castigo y sociedad moderna. Un estudio de teoría social. Siglo XXI, México D.F.

Ginzburg, Carlo (1999), El queso y los gusanos. Muchnik Editores, Barcelona.

Goffman, Erving (1970), Internados. Ensayo sobre la situación social de los enfermos mentales. Amarrortu Editores, Buenos Aires.

Gutiérrez, Juan y Delgado, Juan (1999), “Teoría de la observación”, En: Juan Gutiérrez y Juan Delgado (Eds.). Métodos y técnicas cualitativas de investigación en Ciencias Sociales. Edit. Síntesis Sociológica, Madrid.

Jiménez, Juan Pablo (2008), “Penitencia y conversión: engaste entre religión y dispositivo penitenciario”. En: Revista de Estudios Criminológicos y Penitenciarios, $\mathrm{N}^{\circ}$ 12, Ministerio de Justicia- Gendarmería de Chile y UNICRIM.

Lalive D’Epinay, Christian (2009), El refugio de las masas. Estudio sociológico del protestantismo chileno. Concepción: CEEP Ediciones.

MANSILLA, Miguel Ángel (2007a), Despreciados y desechados: Itinerario de la canutofobia en Chile en la primera mitad del siglo XX. En: Revista Cultura y Religión, Universidad Arturo Prat, Iquique, Vol. 1, №2, Iquique, Universidad Arturo Prat.

Ídem (2007b), La canutofobia en Chile: Los factores socioculturales de la discriminación evangélica. En: Ciencias Sociales Online, Vol. I, № 1, Universidad de Viña del Mar, Chile, <http://www.uvm.cl/csonline>, [Consulta: 6 de septiembre de 2010]

Marín, Nelson (2010), “La Representación Social del Diablo en el Pentecostalismo: Un estudio de caso en Santiago de Chile”. En: Revista Cultura y Religión, Vol. 4, N². Universidad Arturo Prat, Iquique. 
Martínez, Piedad (2006), “El método de estudio de caso. Estrategia metodológica de investigación científica”. En: Pensamiento y Gestión, N 20, Universidad del Norte, <http://redalyc.uaemex.mx/pdf/646/ 64602005.pdf>, [consultado 2 de agosto de 2012], Barranquilla.

Neira, Manuel (2004), “Jeremy Bentham y el liberalismo en Chile durante la primera mitad del siglo XIX”. En: Boletín de la Academia Chilena de Historia, año LXX, N¹13, Santiago.

Pujadas, Juan (2000), “El método biográfico y los géneros de la memoria”. En: Revista de Antropología Social, N 9: 127-158, Madrid.

ReyesS, Pedro y Hernández, Aymara (2008), El Estudio de Caso en el contexto de la Crisis de la Modernidad., En: Cinta Moebio, Universidad de Chile, <www.moebio.uchile.cl/32/reyes.html > [consultado el 10 de agosto 2012], Santiago.

Saldivia-Maldonado, Zenobio \& Caro-Pozo, Felipe (2010), “Alcances sobre el Modelo Panóptico en la Arquitectura Penitenciaria y Médica Chilena”. En: Latin American Journal of International Affairs, Vol. 2, N 3, Art. 02.

Santamarina, Cristina, y Marina, José Miguel (1999), “Historias de vida e Historia Oral”. En: Juan Gutiérrez y Juan Delgado (Eds.), Métodos y técnicas cualitativas de investigación en Ciencias Sociales. Edit. Síntesis Sociológica, Madrid.

Stippel, Jörg (2006), Las cárceles y la búsqueda de una política criminal para Chile. LOM Ediciones, Santiago de Chile.

Taylor, Steven, y Bogdan, Robert (1987), Introducción a los métodos cualitativos de investigación. Editorial Paidós, Barcelona.

Tijoux, María Emilia (2011), “El infierno en la torre 5: Reflexiones sobre la cárcel en Chile”. En: Revista Latinoamericana de estudios sobre Cuerpos, Emociones y Sociedad, N 5, Año 3, Argentina.

Wacquant, Loïc (2004), Cárceles de la miseria. Ediciones Manantial, Buenos Aires.

Ídem (2007), Parias urbanos. Marginalidad en la ciudad a comienzos del milenio. Ediciones Manantial, Buenos Aires.

Watanabe, José (2009), “Pensamiento pentecostal: Un acercamiento a la cosmovisión pentecostal”. En: Voces del Pentecostalismo Latinoamericano III. Identidad, teología, historia. RELEP, Concepción.

Weber, Max (1994) La ética protestante y el espíritu del capitalismo. Ediciones Península, Barcelona. 
Polis, Revista Latinoamericana, Volumen 15, $N^{\circ}$ 43, 2016

Ídem (1999), La Sociología de la Religión. Ediciones el Aleph.com, <http:/ / ww w. cholonautas.edu.pe/modulo/upload/Weber\%20 \%20Sociologia\%20de\%20la\%20Religion.Pdf> [consultado el 25 de julio de 2011].

Yacuzzi, Enrique (2005), “El estudio de caso como metodología de investigación: teoría, mecanismos causales, validación”. En: CEMA Working Papers: Serie Documentos de Trabajo, N 296, Universidad del CEMA, $<$ http://www.ucema.edu.ar/publicaciones/download/documentos/296.pdf>, [consultado el2 de septiembre de 2012].

Yin, Robert (2003), Case study research. Design and methods. Applied Social Research Methods Series, Vol. 5, Sage Publications, California.

Recibido: 19.10.2014

Aceptado: 30.06.2015 